NBSIR 87-3504

\title{
Epoxy Impregnation of Hardened Cement Pastes for Characterization of Microstructure
}

L. Struble

E. Byrd

U.S. DEPARTMENT OF COMMERCE

National Bureau of Standards

National Engineering Laboratory

Center for Building Technology

Gaithersburg, MD 20899

November 1986

Progress Report

Prepared for:

QC - rce Office of Scientific Research

100 irce Systems Command, USAF

.456

g AFB, DC 20332

$87-3504$

1986

C. 2 
NATINAL INSTITUTE OF STANDARDS \&

TECHNOLOGY

Research Information Center

Gaithersburg, MD 20899

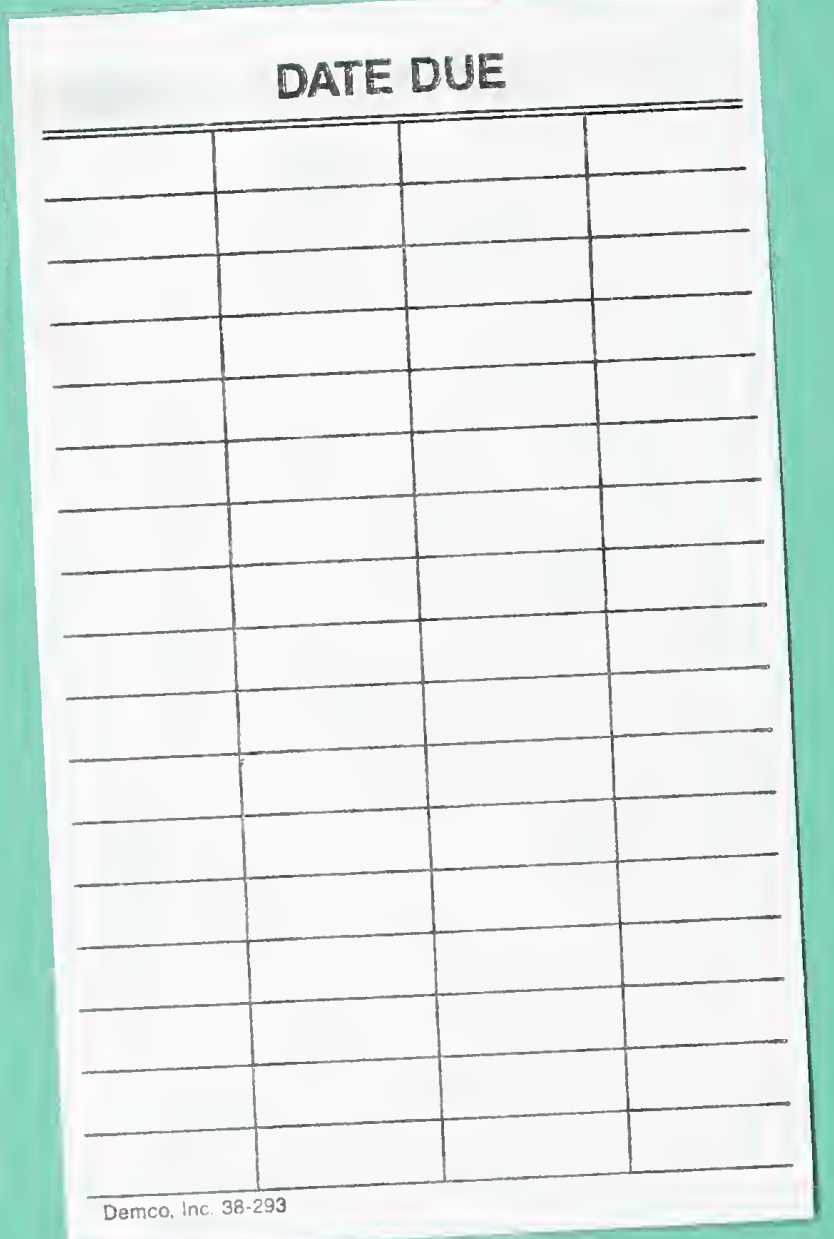




\section{EPOXY IMPREGNATION OF HARDENED}

CEMENT PASTES FOR

\section{CHARACTERIZATION OF MICROSTRUCTURE}

\section{Struble \\ E. Byrd}

U.S. DEPARTMENT OF COMMERCE

National Bureau of Standards

National Engineering Laboratory

Center for Building Technology

Gaithersburg, MD 20899

November 1986

Progress Report

Prepared for:

Air Force Office of Scientific Research

Air Force Systems Command, USAF

Bolling AFB, DC 20332

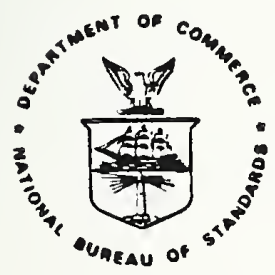

U.S. DEPARTMENT OF COMMERCE, Malcolm Baldrige, Secretary NATIONAL BUREAU OF STANDARDS, Ernest Ambler, Director 
- 

ABSTRACT
Methods were explored for drying of hardened cement paste prior to impregnation with epoxy, in order to polish for microscopic examination. All were shown to cause microcracking of the paste. An alternative method has been developed for epoxy impregnation of hydrated cement specimens without drying the specimens. The method involves replacing pore water with ethanol, then replacing ethanol with epoxy. The method appears to minimize the occurrence of microcracks associated with drying. 



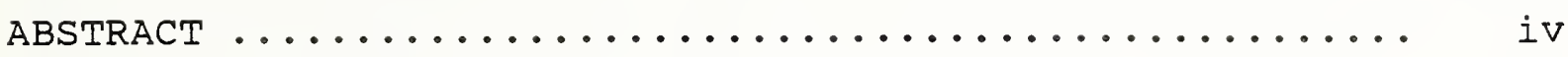

I. INTRODUCTION $\ldots \ldots \ldots \ldots \ldots \ldots \ldots \ldots \ldots \ldots \ldots \ldots$

II. EXPERIMENTAL APPROACH $\ldots \ldots \ldots \ldots \ldots \ldots \ldots \ldots \ldots, 2$

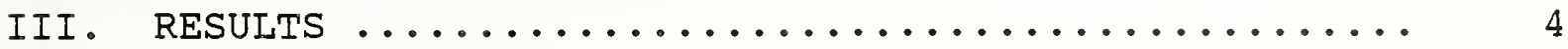

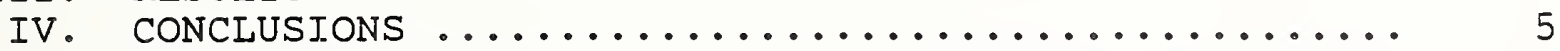

V. ACKNOWLEDGEMENTS $\ldots \ldots \ldots \ldots \ldots \ldots \ldots \ldots \ldots \ldots \ldots \ldots \ldots \ldots$

VI. REFERENCES $\ldots \ldots \ldots \ldots \ldots \ldots \ldots \ldots \ldots \ldots \ldots \ldots \ldots \ldots \ldots \ldots \ldots \ldots \ldots$

\section{IIST OF TABLES}

Table 1. Methods used to dry specimens prior to epoxy

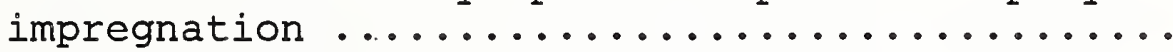

Table 2. Procedure adopted for epoxy impregnation of hardened cement paste by step-wise replacement of pore water with epoxy $\ldots \ldots \ldots \ldots \ldots \ldots \ldots$

\section{LIST OF FIGURES}

Figure 1. BEI micrograph of vacuum-dried, epoxyimpregnated cement paste, large, widely-spaced

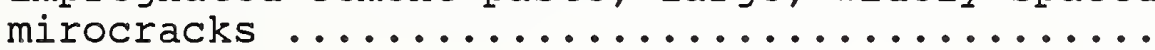

Figure 2. BEI micrograph of methanol-replaced, vacuumdried, epoxy-impregnated cement paste, showing

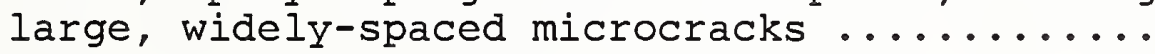

Figure 3. BEI micrograph of freeze-dried, epoxyimpregnated cement paste, showing large,

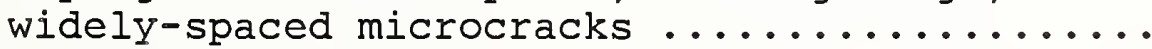

Figure 4. BEI micrograph of cement paste slice (1-mm), whose pore water was sequentially replaced by ethanol, then ethanol replaced by epoxy, showing small microcracks ..............

Figure 5. BEI micrograph of cement paste slice (1-mm), whose pore water was replaced by ethanol in a single step, then ethanol replaced by epoxy,

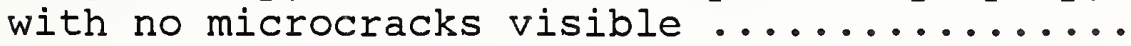

Figure 6. BEI micrograph at higher magnification of the same region as Fig. 5, apparently free of

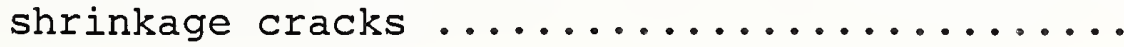



Preparing a polished specimen of hydrated portland cement, or other porous material, requires that the pores first be filled with a hard material such as epoxy. The hard material serves to stabilize the delicate microstructure, providing physical support to prevent damage to the microstructure during polishing. The microstructure may then be examined directly, using such instruments as an optical microscope, scanning electron microscope (SEM), or transmission electron microscope.

Preparation of epoxy-impregnated specimens for polishing is made difficult by the very small pores found in hydrated cement. Much of the pore volume of hydrated cement paste occurs in submicrometer-sized pores, and diffusion of liquid through these pores tends to be slow. Therefore, filling of the pores by epoxy or other liquid is generally achieved by vacuum impregnation, i.e. by immersing the specimen in epoxy while under a vacuum, then bringing the system to atmospheric pressure to force epoxy into pores. However, the pores may contain a considerable amount of liquid water or solution. The specimens must be dried prior to impregnation, and removal of water from the small pores produces shrinkage, which typically causes microcracking. For this reason, specimens that have been dried, impregnated, and polished tend to be highly microcracked, as noted by Chatterji et al (1).

The work described here is part of a wider study of microstructure and fracture. The mechanical properties of concrete, particularly fracture and strength, are widely acknowledged to depend on microstructure, and the principal microstructural features affecting fracture appear to be microcracks 1 and pores (3). Due to the tendency of concrete to form microcracks when exposed to the vacuum required for SEM, Ollivier (4) developed an indirect method to study concrete cracks, examining by SEM an acetylcellulose replica of the concrete surface.

The work described here was undertaken to develop an impregnation method that does not induce microcracks, to allow direct examination of the microstructure. Several methods were explored: vacuum drying, vacuum drying after solvent replacement, freeze drying, and gradual replacement of water by epoxy without drying. Solvent replacement is a commonly used procedure in which the water is replaced by another liquid with lower surface tension. On drying, evaporation of the replacement liquid causes significantly less stress due to its lower surface tension. Parrott (5) discussed drying hydrated cement by a solvent replacement process and concluded that it caused less alteration

${ }^{1}$ In this context, microcracks are considered to be cracks $0.1 \mathrm{~mm}$ or less in width (2). 
to the microstructure than direct removal of the pore water. Freeze drying is another technique used to reduce artifacts caused by drying. At the transition from ice to vapor, there is effectively no surface tension, and drying stresses are greatly reduced. Scrivener and Pratt (6) used freeze drying, followed by vacuum impregnation of epoxy, to prepare hydrated cement for SEM analysis, but they did not assess drying cracks or other artifacts. The final method, gradual replacement of water by ethanol followed by replacement of ethanol by epoxy, is a procedure used for preparing biologic samples.

Impregnated, polished specimens are required in order to examine the microstructural features of hardened cement paste by SEM using backscattered electron imaging (BEI). The typical mode of SEM operation is examination of fracture surfaces; SEM provides a large depth of focus, and spatial resolution necessary to resolve micrometer and submicrometer-sized features. Therefore, our understanding of the microstructure of hardened cement paste, as reviewed recently by Diamond (7), is derived principally from examination of fracture surfaces using SEM. Diamond also described an alternative method used recently to study the microstructure of hardened cement, the examination of polished surfaces using an SEM equipped with a backscattered electron detector. SEM examination of fracture surfaces utilizes a detector that collects both secondary and backscattered electrons and provides contrast principally by relief, or surface roughness. Backscattered electron detection of a smooth sample, however, provides contrast only by atomic number difference. Using BEI allows one to differentiate between constituents on the basis of chemical composition. The method has been shown to be effective in studying the microstructure of clinker and of hydrated cement $(8,9,6)$. A particular advantage in the present study is that epoxy-filled pores and cracks may be readily differentiated from other constituents. An additional advantage is provided by the planar specimen, since the image of a two-dimensional surface is amenable to quantitative analysis, for example using a computer image-analysis system.

\section{EXPERIMENTAL APPROACH}

Hardened cement paste samples were used to assess impregnation methods for michostructure examination. The paste was prepared using a Type $I^{2}$ portland cement and deionized water, at a waterto-cement ratio of 0.35 (by mass). These were mixed in a blender as follows: mixed for $1 \mathrm{~min}$, allowed to rest for $2 \mathrm{~min}$, and remixed for $1 \mathrm{~min}$. The paste was cast into $10 \mathrm{~mm}$ cube molds, allowed to cure in the molds for $24 \mathrm{~h}$, then demolded and immersed in saturated $\mathrm{Ca}(\mathrm{OH})_{2}$ solution for curing.

${ }^{2}$ According to ASTM Standard Specification for Portland Cement ( C150-81). 
After curing for several weeks, specimens were either dried and vacuum impregnated with epoxy, or impregnated with epoxy without drying. In some cases, the entire $10 \mathrm{~mm}$ cube was dried, and in some cases a 1-mm slice of this cube specimen was used; slices were cut using a low-speed, diamond saw ${ }^{3}, 4$.

The dried specimens were prepared using the various drying techniques listed in Table 1. After drying, specimens were vacuum impregnated with a low-viscosity epoxy ${ }^{5}$, using the following procedure: 1) the dried specimen was placed in a reaction vessel, described elsewhere (10), and evacuated to a pressure of $\sim 3 \mathrm{kPa}$ for $\sim 30 \mathrm{~min} ; 2$ ) the specimen was immersed in epoxy while still under vacuum, and the vacuum maintained for no longer than 3 min; 3 ) the vacuum was released slowly and compressed air added to provide a pressure of $0.5 \mathrm{MPa}$ for at least $10 \mathrm{~min}$; and 4 ) the epoxy was allowed to harden under ambient conditions.

The other process, in which pore water was replaced by epoxy without drying, utilized a low-viscosity, ethanol-miscible epoxy 6 that is thermally cured. The process involved two steps, first replacing pore water with ethanol, then replacing ethanol with epoxy. The process was applied both to the $1000-\mathrm{mm}^{3}$ cubes and to 1-mm slices. Two procedures were used to replace water with ethanol. One was a sequential replacement procedure, in which the specimen was progressively immersed in a series of ethanol and water mixtures: first a 50:50 mixture, then a 75:25 mixture, and finally $100 \%$ ethanol. The specimen was immersed for 24 hours in each solution. The other was a single-step procedure, in which the specimen was immersed in 100\% anhydrous ethanol for 4 days. After replacing water with ethanol, the ethanol was replaced with epoxy by immersing the specimen in a 50:50 mixture of ethanol and epoxy for approximately 24 hours, then in 100\% epoxy for 24 hours. Finally, the epoxy was cured at $60^{\circ} \mathrm{C}$ for 2 to 3 days until hard. Once cured, it proved necessary to minimize contact of the hardened epoxy with water vapor, since exposure for a few days to ambient air caused the epoxy to soften.

${ }^{3}$ Certain trade names and company products are identified to specify adequately the experimental procedure. In no case does such identification imply recommendation or endorsement by the National Bureau of Standards, nor does it imply that the products are necessarily the best available for the purpose.

${ }^{4}$ Isomet saw, Buehler, Ltd.

5Epo-tek 301, Epoxy Technology, Inc.

${ }^{6}$ Spurrs ultra-low viscosity embedding medium, Polysciences, Inc. 
For low-viscosity epoxies, such as the two used in these experiments, it is important to note that there may be safety hazards, and the manufacturer's instructions must be followed precisely.

Impregnated specimens were ground and polished following standard metallographic procedures, but using a nonaqueous medium. Specimens were examined for microcracks using an SEM 7 equipped with a Robinson backscattered electron detector.

\section{III . RESULTS}

SEM micrographs of all dried and vacuum-impregnated specimens (Figs. 1 to 3) indicate considerable microcracking, regardless of the drying method. The microcracks form a pattern comprised of 3-node cracks, $120^{\circ}$ apart; this pattern is believed to result from drying shrinkage. The vacuum-dried specimen (Fig. 1) contained a large number of large and widely-spaced microcracks, typically $5 \mu \mathrm{m}$ to $10 \mu \mathrm{m}$ wide and a few hundred $\mu \mathrm{m}$ apart. The specimen whose pore water was replaced with methanol prior to vacuum-drying contained comparable microcracks (Fig. 2), and freeze-drying likewise produced large and widely-spaced microcracks (Fig. 3).

The specimen ( $10 \mathrm{~mm}$ cube) prepared by sequential replacement of pore water by ethanol and replacement of ethanol by epoxy contained microcracks, but they were considerably smaller than the microcracks in the dried specimens described above. To determine how deep the epoxy had penetrated, this specimen was cut in half along a plane normal to the top surface, and one half was polished to provide a side view. Examination by SEM indicated that the epoxy had penetrated only to a depth of $0.2 \mathrm{~mm}$ to 0.3 $\mathrm{mm}$. Therefore, a $1-\mathrm{mm}$ slice cut from a cement paste specimen was prepared using the sequential replacement process. (A $1-\mathrm{mm}$ thickness was considered sufficiently thin to be largely penetrated by ethanol and epoxy, but sufficiently thick for cutting and polishing.) SEM examination (Fig. 4) indicated that this 1-mm slice, prepared by sequential replacement of pore water by ethanol and replacement of ethanol by epoxy, contained only a few. microcracks, no more than $2 \mu \mathrm{m}$ wide.

To explore whether the sequential replacement of water by ethanol is necessary for hardened cement paste, two specimens were prepared using the single-step replacement. One specimen (Fig. 5) was free of microcracks; the other specimen contained only a few regions with small, widely spaced microcracks.

When examined at higher magnification, these specimens were seen to contain very fine microcracks, $\sim 0.5 \mu \mathrm{m}$ wide and $\sim 20 \mu \mathrm{m}$

${ }^{7}$ ISI-40, International Scientific Instruments. 
long. These finer microcracks, shown in Fig. 6, were much shorter than the shrinkage cracks observed in the dried specimens, and not branched. While these very fine cracks do not appear to result from drying, it is possible that they are incipient drying shrinkage cracks. Alternative explanations are that they are caused by the cutting operation, or that they are a normal feature of hydrated cement.

\section{CONCLUSIONS}

A number of methods to dry cement paste prior to vacuum impregnation of epoxy were explored, and all methods were found to cause microcracking. When the pore water in a $1-\mathrm{mm}$ slice of cement paste was replaced by ethanol and the ethanol by epoxy without drying the specimen, the occurrence of microcracks due to drying was substantially reduced or eliminated. It appears that pore water may be replaced by ethanol using either a sequential replacement or a single-step replacement. Based on these results, the impregnation procedure summarized in Table 2 has been adopted in our laboratory to prepare epoxy-impregnated specimens free of drying cracks for SEM examination. 


\section{ACKNOWLEDGEMENTS}

The technical assistance provided by Mr. F. Davis and by Mr. W. Roberts is gratefully acknowledged. The research described was sponsored by the Air Force Office of Scientific Research, Air Force Systems Command, USAF, under Grant Number AFOSR-155A860057 . 
VI. REFERENCES

1. S. Chatterji, N. Thaulow, and P. Christensen. Formation of shrinkage cracks in thin specimens of cement paste. Cement and Concrete Research, 11(1), 155-157 (1981).

2. F.O. Slate. Microscopic observation of cracks in concrete, with emphasis on techniques developed and used at cornell University. In: Fracture Mechanics of Concrete, ed. by E.H. Wittmann, pp. 75-83. New York: Elsevier (1983).

3. F.H. Wittmann. Structure of concrete with respect to crack formation. In: Fracture Mechanics of Concrete, ed. by F.H. Wittmann, pp. 43-74. New York: Elsevier (1983).

4. J.P. Ollivier. A non destructive procedure to observe the microcracks of concrete by scanning electron microscopy. Cement and Concrete Research, 15(6), 1055-1060 (1985).

5. I.J. Parrott. Novel methods of processing cement gel to examine and control microstructure and properties. Phil. Trans. R. Soc. London, A, 310, 155-166 (1983).

6. K.I. Scrivener and P.I. Pratt. Backscattered electron images of polished cement sections in the scanning electron microscope. In: Proceedings of the Sixth International Conference on Cement Microscopy, pp. 145-155. Duncanville: ICMA (1984).

7. S. Diamond. The microstructures of cement paste in concrete. In: Proceedings of the 8 th International Congress on the Chemistry of Cement, Volume I, 122-147 (1986).

8. A.P. Barker, P. Barnes, G.R. Fisher, and H. Jennings. Novel microscopy techniques for studying the microstructure of clinkers and hydrated cements - some preliminary results. In: Proceedings of the Sixth International Conference on Cement Microscopy, pp. 5-19. Duncanville: ICMA (1984).

9. A.P. Barker and P. Barnes. A review of techniques for phase delineation within cement in the scanning electron microscope. In: Proceedings of the Sixth International Conference on Cement Microscopy, pp. 156-172. Duncanvilie: ICMA (1984).

10. J.R. Clifton, J.E. Eearn, and E.D. Anderson. Polymer impregnated cement pastes and mortars. National Bureau of Standards (U.S.) Building Science Series 83, 16 pages. Washington: U.S. Department of Commerce (1976). 
Table 1. Methods used to dry specimens prior to epoxy impregnation. Method No. Description of Method

Vacuum drying: cube, $10 \mathrm{~mm} \times 10 \mathrm{~mm} \times 10 \mathrm{~mm}$, exposed to modest vacuum $(\sim 30 \mathrm{kPa})$ for 1 day. Solvent replacement: cube, $10 \mathrm{~mm} \times 10 \mathrm{~mm} 10 \mathrm{~mm}$, immersed in methanol for 1 day, then vacuum dried using Method No. 1.

Freeze drying: slice, $1 \mathrm{~mm} \times 10 \mathrm{~mm} \times 10 \mathrm{~mm}$, cooled to $-75^{\circ} \mathrm{C}$, then exposed to a strong vacuum $(0.1 \mathrm{~Pa})$ for ${ }^{3}$ days. 
Table 2. Procedure adopted for epoxy impregnation of hardened cement paste by step-wise replacement of pore water with epoxya.

Step No. Description of step

1 Single-step replacement of water by ethanol, by immersing specimen (1-mm thick slice) in $100 \%$ anhydrous ethanol for 4 days.

2 Immerse specimen in a 50:50 mixture of anhydrous ethanol and epoxy for 24 hours.

3 Immerse in epoxy for 24 hours

4 Cure epoxy at $60^{\circ} \mathrm{C}$ for 2 days

a Spurrs ultra-low viscosity embedding medium, Polysciences, Inc. 


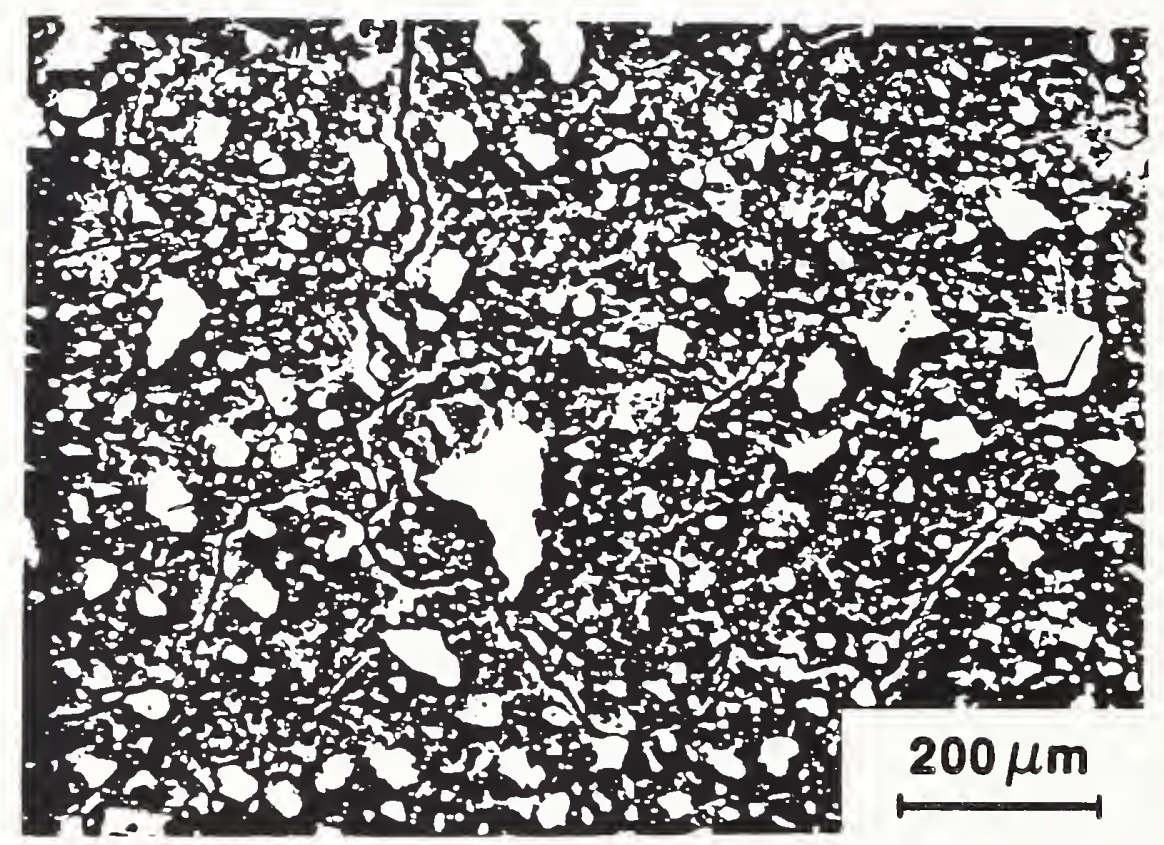

Figure 1. BEI micrograph of vacuum-dried, epoxy-impregnated cement paste, showing large, widely-spaced microcracks. 


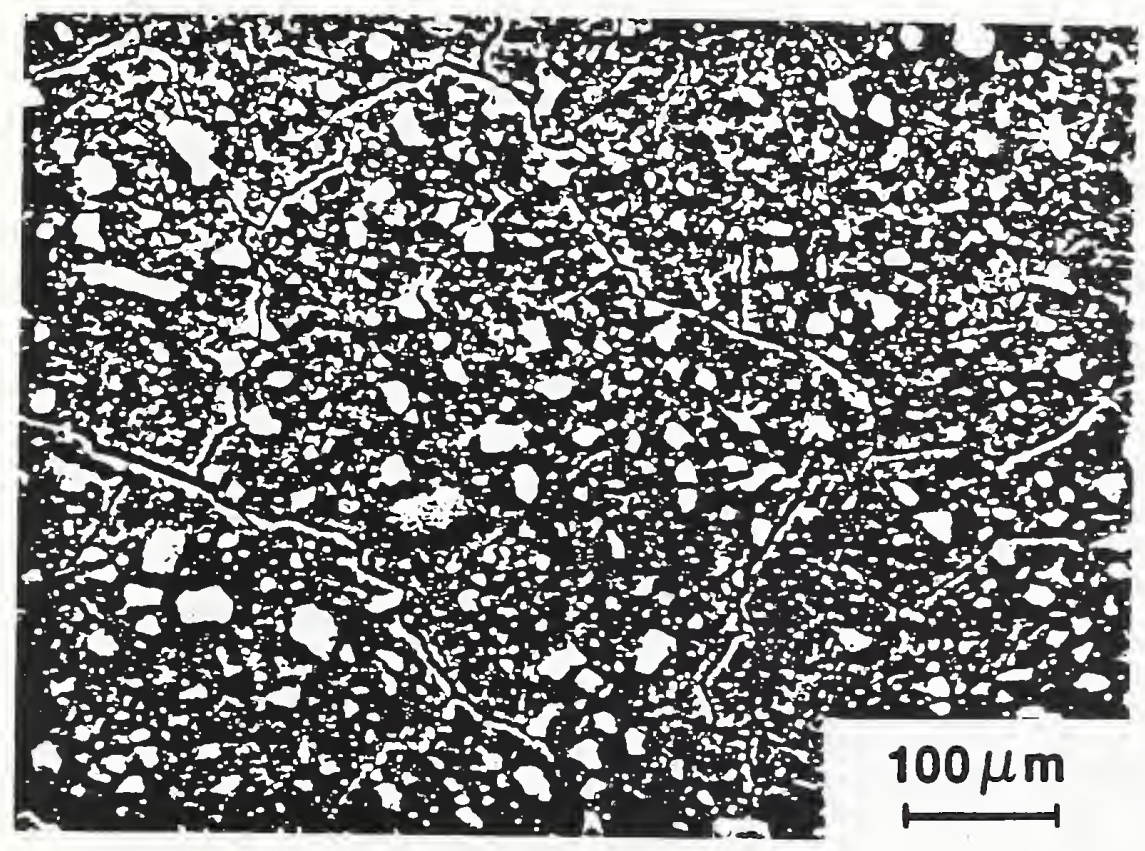

Figure 2. BEI micrograph of methanol-replaced, vacuum-dried, epoxy-impregnated cement paste, showing large, widelyspaced microcracks. 


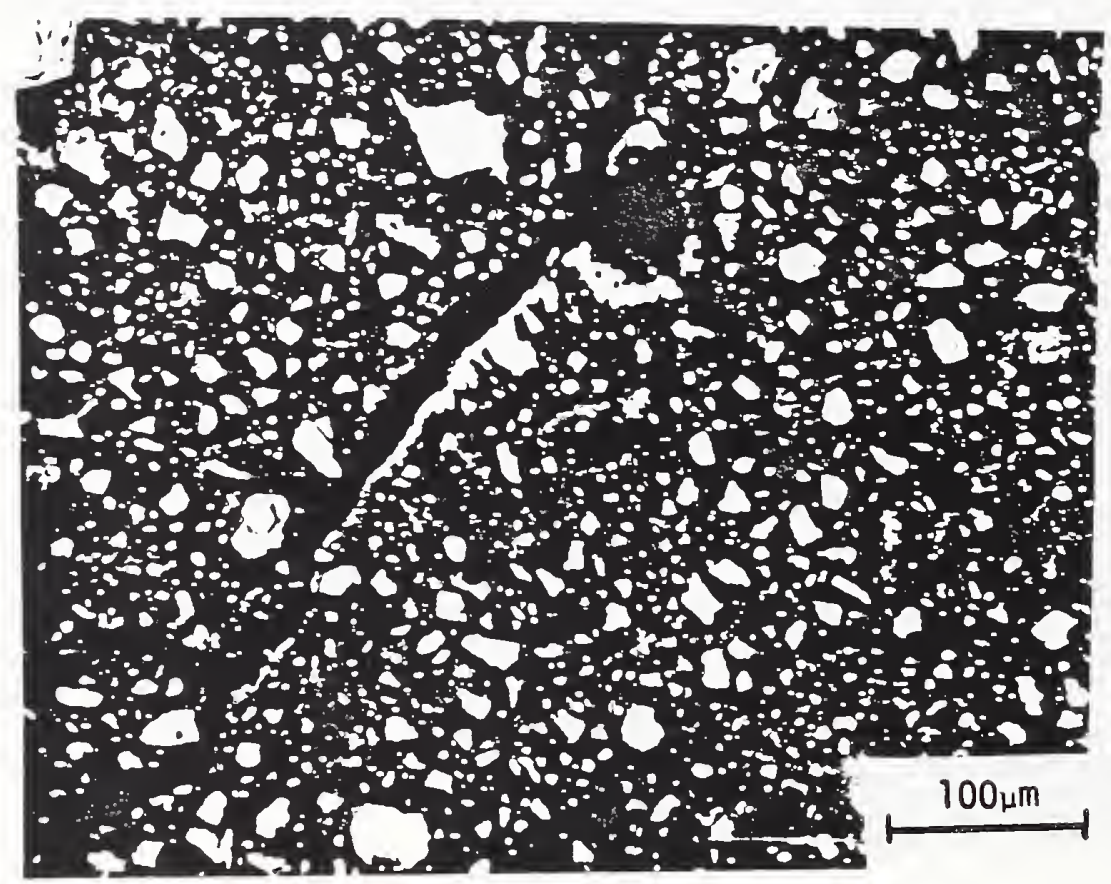

Figure 3. BEI micrograph of freeze-dried, epoxy-impregnated cement paste, showing large, widely-spaced microcracks. 


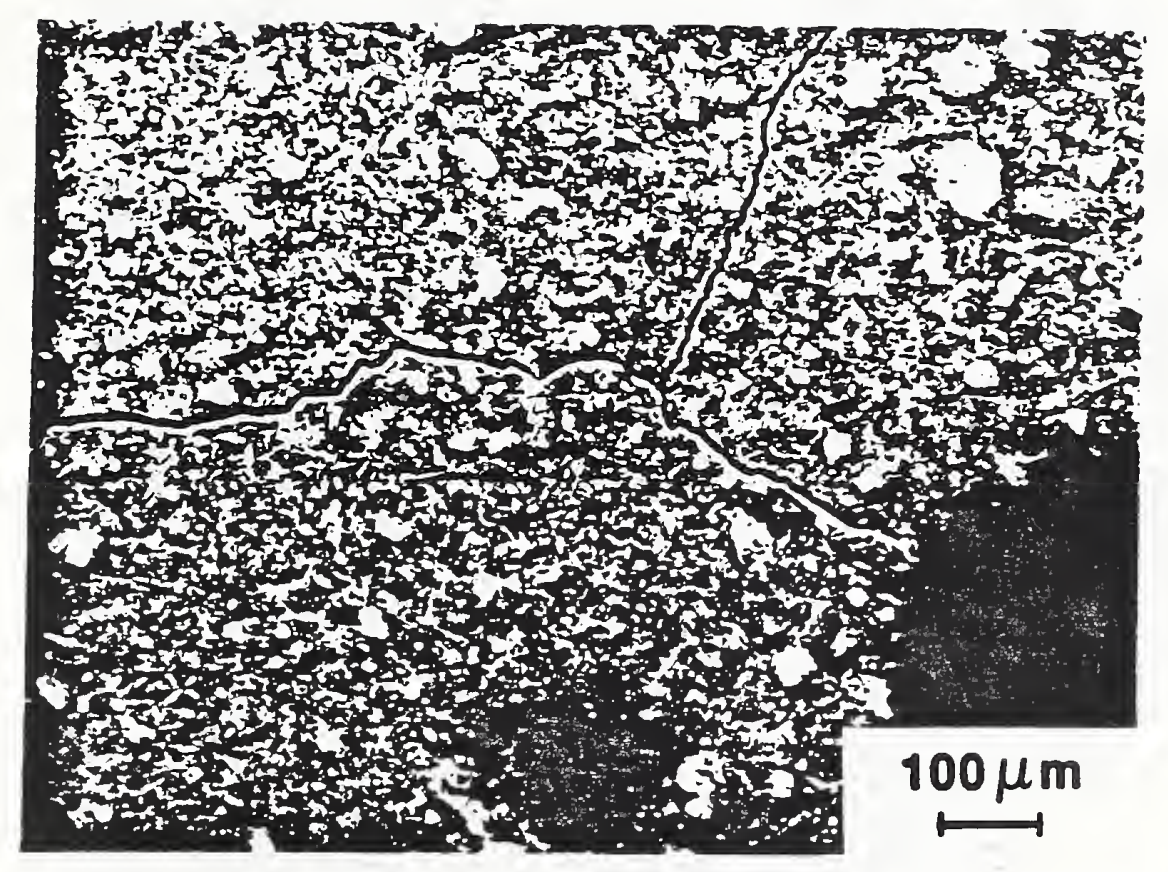

Figure 4. BEI micrograph of cement paste slice (1-mm), whose pore water was sequentially replaced by ethanol, then ethanol replaced by epoxy, showing small microcracks. 


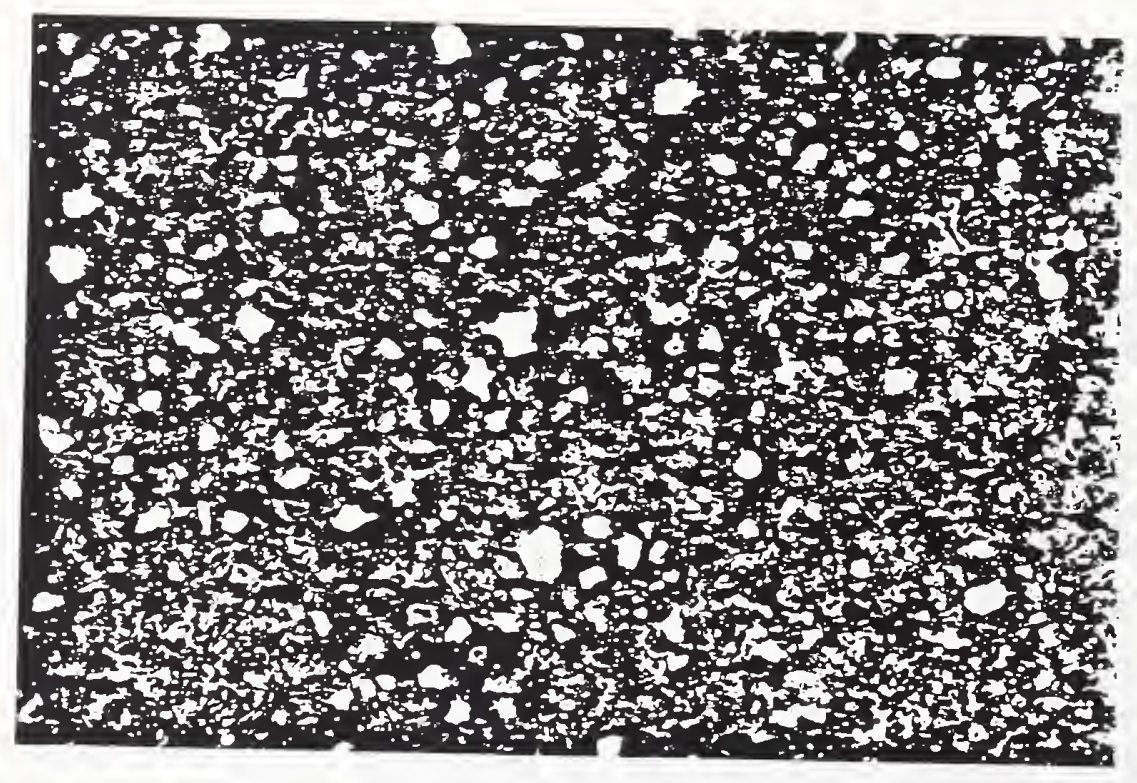

$100 \mu \mathrm{m}$

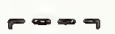

Figure 5. BEI micrograph of cement paste slice (1-mm), whose pore water was replaced by ethanol in a single step, then ethanol replaced by epoxy, with no microcracks visible. 


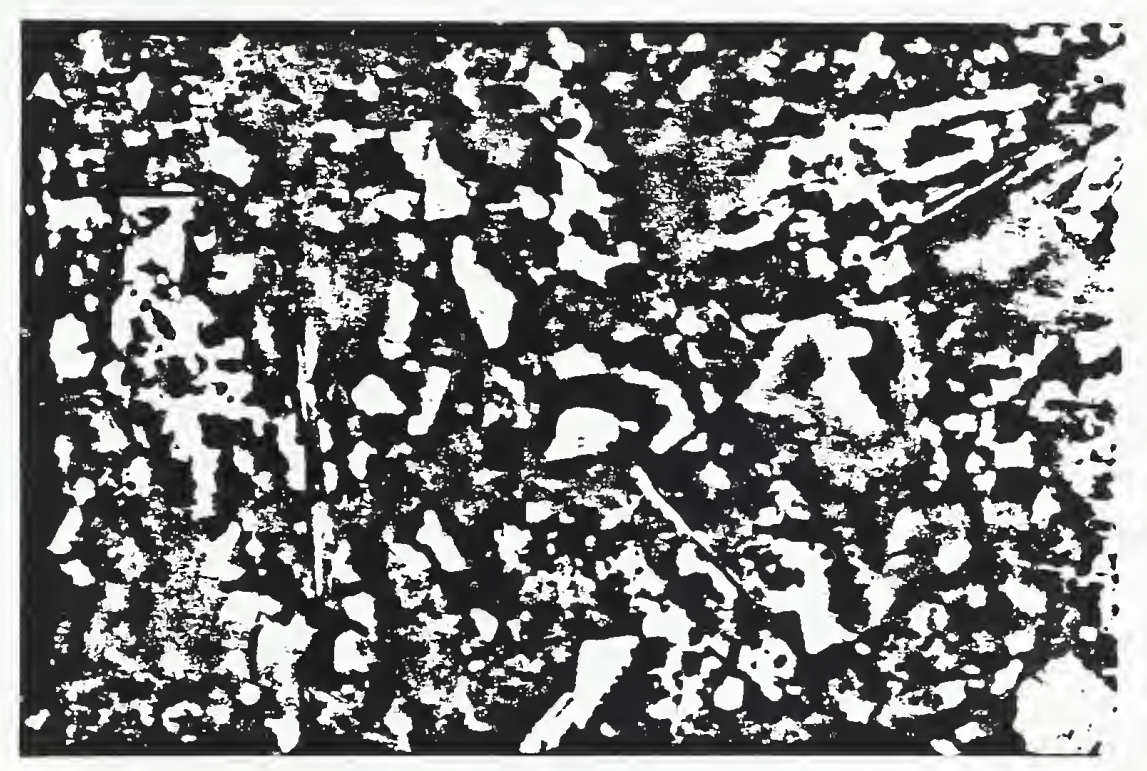

$10 \mu \mathrm{m}$

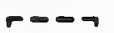

Figure 6. BEI micrograph at higher magnification of the same region as Fig. 5, apparently free of shrinkage cracks. 
NBS-114A (REV. 2.80)

U.S. DEPT. OF COMM.

BIBLIOGRAPHIC DATA

SHEET (See instructions)

1. PUBLICATION OR REPORT NO.

NBSIR $87-3504$

4. TITLE AND SUBTITLE

Epoxy Impregnation of Hardened Cement Pastes for Characterization

of Microstructure

5. $\operatorname{AUTHOR}(S)$

L. Struble and $E$. Byrd

6. PERFORMING ORGANIZATION (If joint or other than NBS, see instructions)

NATIONAL BUREAU OF STANDARDS

DEPARTMENT OF COMMERCE

WASHINGTON, D.C. 20234

- Contract Grant No.

AFOSR-155A86-C057

8. Type of Report \& Period Covered

Interim Proaress Report

9. SPONSORING ORGANIZATION NAME AND COMPLETE ADDRESS (Street, City, State, ZIP)

Air Force Office of Scientific Research

Air Force Systems Command, USAF

Bolling AFB DC 20332

10. SUPPLEMENTARY NOTES

Document describes a computer program; SF-185, FIPS Software Summary, is attached.

11. ABSTRACT (A 200-word or less foctual summary of most significant information. If document includes a significant

bibliography or literature survey. mention it here)

Methods were explored for drying of hardened cement

paste prior to impregnation with epoxy, in order to polish

for microscopic examination. All were shown to cause

microcracking of the paste. An alternative method has been

without drying the specimens. The method involves replacing

pore water with ethanol, then replacing ethanol with epoxy.

The method appears to minimize the occurrence of microcracks

associated with drying.

12. KEY WOROS (Six to twelve entries; olphabetical order; capitalize only proper names; and separate key words by semicolons) cement; concrete; epoxy; impregnation; microscopy; microstructure;

Scanning Electron Microscope

13. AVAILABILITY

$\mathrm{X}$ Untimited

$\square$ For Official Distribution. Do Not Release to NTIS

$[$ Order From Superintendent of Documents, U.S. Government Printıng Office, Washington, D.C. 20402.

区] Order From National Technical Information Service (NTIS), Springfield, VA. 2216I
14. NO. OF

PRINTED PAGES

20

15. Price

$\$ 9.95$ 
